\title{
Seborrhoea is not a feature of seborrhoeic dermatitis
}

\author{
J L BURTON, R J PYE
}

\begin{abstract}
The sebum excretion rate from forehead skin was measured in 44 patients with classic seborrhoeic dermatitis and 200 control subjects. The mean excretion rate was normal in the 29 men with seborrhoeic dermatitis and significantly reduced in the 15 women with the disease.

This study showed that seborrhoeic dermatitis is not usually associated with seborrhoea, and therefore "dermatitis of the sebaceous areas" may be a more accurate term.
\end{abstract}

\section{Introduction}

The role of seborrhoea in the pathogenesis of seborrhoeic dermatitis is debatable. Active sebaceous glands appear to be necessary for the development of the disorder, since it is rare before puberty and tends to affect sites such as the scalp, face, and upper trunk, which are rich in large sebaceous glands. Many patients with the condition apparently have a greasy skin, ${ }^{12}$ although some authors refute this. ${ }^{34}$ The few attempts to measure the rate of sebum excretion in seborrhoeic dermatitis have given conflicting results. Hodgson-Jones et $a l^{5}$ found a normal rate, whereas El-Mofty $e t a l^{6}$ in a smaller study claimed that it was increased.

We have used a more accurate method to measure the forehead sebum excretion rate and report the results in patients with seborrhoeic dermatitis and a group of controls.

\section{Subjects and methods}

Dermatologists vary in their concept of seborrhoeic dermatitis and in their readiness to diagnose this condition. We therefore studied only patients who had unequivocal seborrhoeic dermatitis, with a red

\footnotetext{
Department of Dermatology, Bristol Royal Infirmary, Bristol BS2 8HW

J L BURTON, MD, FRCP, consultant senior lecturer in dermatology

R J PYE, MD, MRCP, consultant dermatologist

Correspondence to: Dr J L Burton.
}

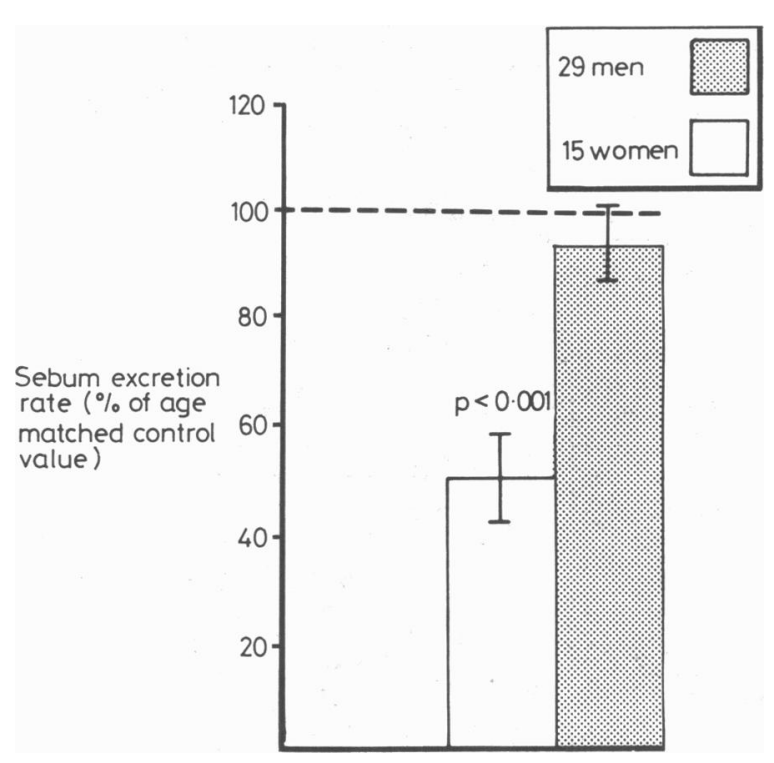

FIG 1-Sebum excretion rates in men and women with seborrhoeic dermatitis.

scaly scalp and the typical eruption in at least one other classic site, for example, face, chest, back, or intertriginous areas. Patients were excluded if the diagnosis was doubtful or if the scalp was not affected. Forty four consecutive patients (aged 18 to 81 years) who fulfilled these criteria were studied, together with 200 adult controls who presented to the same dermatology department with warts or some other localised non-eczematous dermatosis which did not affect the forehead. The sebum excretion rate in each subject was measured from forehead skin by the modified gravimetric method. ${ }^{78}$

\section{Results}

The sebum excretion rate was expressed throughout as a percentage of control values matched for sex and age to the nearest decade. The mean excretion rate in the men with seborrhoeic dermatitis was normal $(94 \pm$ SE $7 \%$ ) but that in the women patients was reduced $(51+$ SE $8 \%)$, the decrease being highly significant $(p<0.001)$ (fig 1 ). Since sebum excretion varies with age and sex, the patients were also divided into three age groups for each sex-20-39 years, $40-59$ years, 
and 60-79 years (fig 2). The few patients aged under 20 or over 79 were included in the age group nearest their own. In the male patients the values did not differ significantly from normal but in the women the rate was decreased at all ages, and in the two older age groups these differences were significant $(\mathrm{p}<0.02)$.

Dividing the patients clinically into those with mild, moderate, and severe seborrhoeic dermatitis showed no relation between the sebum excretion rate and severity of the disease (fig 3 ).

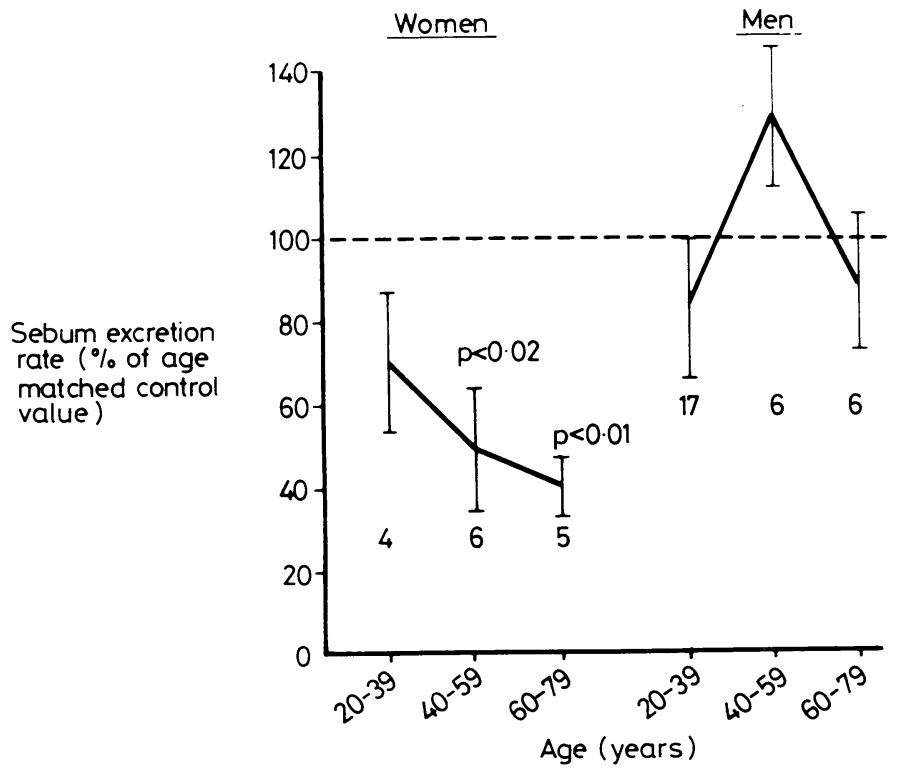

FIG 2-Sebum excretion rates at various ages in patients with seborrhoeic dermatitis (means \pm SE)



FIG 3-Sebum excretion rates in patients with seborrhoeic dermatitis of various degrees of severity (means $\pm \mathrm{SE}$ ).

\section{Discussion}

This study suggests that the term seborrhoeic dermatitis is a misnomer, since the disease is not associated with seborrhoea and women over 40 had a significant reduction in sebum excretion. Further evidence that seborrhoea is not essential to seborrhoeic dermatitis is provided by the observation that a dose of oestrogen sufficient to suppress sebum secretion produces no improvement in patients with seborrhoeic dermatitis.

Acne is associated with seborrhoea, ${ }^{10}$ and some clinicians believe that there is a high prevalence of seborrhoeic dermatitis among patients with acne, but we have been unable to find data to support this. Cohen ${ }^{3}$ found no association between the two disorders in his survey of 500 women, of whom 58 had seborrhoeic dermatitis and 146 clinical acne.

Some textbooks state that seborrhoeic dermatitis may be due to parkinsonism, ${ }^{11}{ }^{12}$ which is known to be associated with seborrhoea. ${ }^{13-15}$ Treatment of parkinsonism with levodopa reduces sebum excretion if seborrhoea is initially present but has no effect on the normal excretion rate. ${ }^{13}$ Parish studied 18 patients with seborrhoeic dermatitis who were treated with levodopa for their parkinsonism, and the three patients who showed a noticeable improvement in their skin condition also had a reduction in sebum excretion. ${ }^{16}$ This is consistent with the suggestion that seborrhoea may play a part in the seborrhoeic dermatitis of some of these patients. The prevalence of seborrhoeic dermatitis in parkinsonism is not known, but it is unlikely to be a common complication: only one of the 31 patients studied by Burton and colleagues had seborrhoeic dermatitis. ${ }^{13} 1517$

Localised seborrhoea may be provoked by a nerve lesion, ${ }^{18}{ }^{19}$ and Bettley and Marten described a patient in whom unilateral seborrhoea and seborrhoeic dermatitis developed on the face after facial nerve paralysis. ${ }^{19}$

Patients commonly labelled as seborrhoeic dermatitis are probably a heterogeneous group. It may be that patients with seborrhoea due to parkinsonism or nerve palsy do have an increased tendency to seborrhoeic dermatitis, but such cases are probably in the minority, and none of our 44 patients with classic seborrhoeic dermatitis had parkinsonism or nerve lesions.

We conclude that seborrhoea plays no part in the pathogenesis of the rash in most patients with seborrhoeic dermatitis, and we think that this misleading term should be dropped. "Dermatitis of the sebaceous areas" would be more accurate.

Thanks are due to the Medical Research Council for financial support and the consultant dermatologists of the Bristol Royal Infirmary for allowing us to study their patients. This work was included in an MD thesis (London University) submitted by RJP.

\section{References}

${ }^{1}$ Ingram JT. Seborrhoeic diathesis. Br Med f 1939;ii:5-8.

${ }^{2}$ Mitchell-Heggs GB. Seborrhoeic dermatitis and acne vulgaris. $\mathrm{Br} \mathrm{Med} 7$ 1951 ;ii:1079-82.

${ }^{3}$ Cohen EL. The relationship of acne with dandruff and seborrhoeic dermatitis. British fournal of Dermatology and Syphilology 1945;57:45-7.

4 Davies JHT. Seborrhoeic eczema: an attempt to define the scope of the term. Br F Dermatol 1952;64:213-24.

${ }^{5}$ Hodgson-Jones IS, MacKenna RMB, Wheatley VR. The surface skin fat in seborrhoeic dermatitis. Br $\mathcal{F}$ Dermatol 1953;65:246-51.

${ }^{6}$ El-Mofty AM, Ismail AA, Abdel-Hay A, Kamel G, Nada M, Talaat M. Skin surface lipid excretion and blood lipids in seborrhoeic disorders. Egypt Med Assoc 1967;50:375-80.

7 Strauss JS, Pochi PE. The quantitative gravimetric determination of sebum production. F Invest Dermatol 1961 ;36:293-8

${ }^{8}$ Cunliffe WJ, Shuster S. The rate of sebum excretion in man. Br $\mathcal{F}$ Dermatol $1969 ; 81: 697-704$.

${ }^{9}$ Pochi PE. Cited by Parish and Arndt. ${ }^{20}$

10 Burton JL, Shuster S. The relationship between seborrhoea and acne vulgaris. Br f Dermatol $1971 ; 84: 600-1$.

11 Shelley WB. Consultations in dermatology II. Philadelphia: W B Saunders Company, 1974:312.

12 Domonkos AN. Andrews' diseases of the skin. Philadelphia: W B Saunders Company, 1971:206

13 Burton JL, Cartlidge M, Shuster S. Effect of L-dopa on the seborrhoea of parkinsonism. Br $\mathcal{F}$ Dermatol 1973;88:475-9.

14 Pochi PE, Strauss JS, Mescon H. Sebum production and fractional 17ketosteroid excretion in parkinsonism. $\mathcal{F}$ Invest Dermatol 1962;38:45.

${ }^{15}$ Burton JL, Cartlidge M, Cartlidge NEF, Shuster S. Sebum excretion in parkinsonism. Br $\mathcal{F}$ Dermatol 1973;88:263-6.

${ }^{16}$ Parish LC. L-Dopa for seborrheic dermatitis. N Englf Med 1970;283:879.

17 Burton JL, Shuster S. Effect of L-dopa on seborrhoea of parkinsonism. Lancet 1970;ii:19-20.

18 Bujadoux A. Seborhec fluente avec hyperesthasie cutanea d'origine. Lyon Medical 1936;157:355-7

19 Bettley FR, Marten RH. Unilateral seborrheic dermatitis following a nerve lesion. Arch Dermatol 1956;73:110-5.

${ }^{20}$ Parish LC, Arndt K. Seborrhoeic dermatitis of the beard. $\mathrm{Br} 7$ Dermatol $1972 ; 87: 241-4$.

(Accepted 22 February 1983) 